\title{
Ocular Manifestations of Metabolic Syndrome
}

\author{
Hamid Reza Rahimi ${ }^{1}$; Arash Omidtabrizi ${ }^{2}$; Majid Ghayour Mobarhan ${ }^{3}$; Fatemeh Sharifi ${ }^{4,5,}$ \\ ${ }^{1}$ Student Research Committee, Department of Modern Sciences and New Technologies, Faculty of Medicine, Mashhad University of Medical Sciences, Mashhad, IR Iran \\ ${ }_{3}^{2}$ Department of Ophthalmology, Mashhad University of Medical Sciences, Mashhad, IR Iran \\ ${ }^{3}$ Cardiovascular Research Center, Faculty of Medicine, Mashhad University of Medical Sciences, Mashhad, IR Iran \\ ${ }_{5}^{4}$ Refractive Errors Research Center, School of Paramedical Sciences, Mashhad University of Medical Sciences, Mashhad, IR Iran \\ 5 Department of Optometry, Faculty of Paramedical Sciences, Mashhad University of Medical Sciences, Mashhad, IR Iran \\ ${ }^{*}$ Corresponding author: Fatemeh Sharifi, Department of Optometry, Faculty of Paramedical Sciences, Vakilabad Blvd., Bahonar Blvd., Pardis Campus, Mashhad University of Medical \\ Sciences, Mashhad, IR Iran. Tel: +98-9153599297, Fax: +98-5118827029, E-mail: opf.sharifi@gmail.com
}

Received: November 29, 2013; Revised: April 6, 2014; Accepted: April 27, 2014

\begin{abstract}
Context: Metabolic syndrome (metabolic syndrome X) is a prevalent cluster of risk factors that include high BMI, hypertension, insulin resistance and dyslipidemia. Individuals with metabolic syndrome are at an increased risk of coronary artery disease (CAD) and diabetes mellitus. Diabetes mellitus and hypertension (HTN) are associated with retinopathy and cataract.

Evidence Acquisition: Bibliographical searches were performed using MEDLINE/ScienceDirect/OVID up to October 2013 using the following keywords (all fields): ("metabolic syndrome” OR "Met syndrome”) AND [(ocular disease) OR (cataract) OR (glaucoma) OR (agerelated maculopathy).

Results: This review explores the relationship between metabolic syndrome, including all its components, and various ocular conditions such as retinopathy, central retinal artery occlusion, cataract and elevated intraocular pressure.

Conclusions: Today, the prevalence of metabolic syndrome is increasing, because world population life in prevalence behaviors have changed. Its association with various ocular manifestations such as non-diabetic retinopathy, CRAO, cataract, and primary open angle glaucoma suggests that an epidemic of Met syndrome can have far-fetched ocular consequences as well.
\end{abstract}

Keywords: Cataract; Retinal Artery Occlusion; Intraocular Pressure; Metabolic Syndrome X; Retinopathy

\section{Context}

Based on Adult Treatment Panel III report (ATP-III) definition, Metabolic Syndrome X (Met syndrome) is the presence of three or more of the following components $(1,2)$ :

1) Abdominal obesity (the abdominal obesity definition was modified using Asia Pacific WHO guidelines as body mass index $[\mathrm{BMI}]>25 \mathrm{~kg} / \mathrm{m}^{2}$ ) (3)

- Elevated blood triglycerides $>150 \mathrm{mg} / \mathrm{dL}(1.7 \mathrm{mM})$

- Low HDL cholesterol < $40 \mathrm{mg} / \mathrm{dL}(1.0 \mathrm{mM})$ in men and $<$ $50 \mathrm{mg} / \mathrm{dL}(1.3 \mathrm{mM})$ in women

- High blood pressure (high BP) > 130/85 mm Hg or use of BP lowering medications

2) Diabetes mellitus defined as a casual plasma glucose $>200 \mathrm{mg} / \mathrm{dL}(11.1 \mathrm{mmol} / \mathrm{L})$ or a self-reported history of physician-diagnosed diabetes $(4,5)$.

It is well established that hypertension and diabetes are in association with ocular conditions such as retinopathy (6), cataract (7), and elevated intraocular pressure (IOP) $(8,9)$. The prevalence of Met Syndrome as defined by the national cholesterol education program (NCEP) guidelines has been estimated using the national health and nutritional examination survey (NHANES) database (10).
Based on the data from NHANES collected between 1999 and 2002, the prevalence of Met Syndrome is $34.5 \%(11,12)$. Also Azimi-Nejad et al. found that the "prevalence of Met syndrome was higher in Iranian women (55.0\%), followed by Iranian men (30.1\%), and this was higher than in French men (13.7\%) and French women (6.6\%) (13).

Nowadays several studies have introduced the notion that an increase of serum levels of inflammatory biomarkers as an emerging risk factor for many chronic diseases, including the metabolic syndrome, and obesity (14, 15). Some cytokines such as IL-2, IL-12, IFN- $\gamma$, TNF- $\alpha$ and TNF$\mathrm{B}$ are pro inflammatory and cause exacerbation in Met syndrome $(16,17)$. These inflammatory cytokines might develop or worsen other diseases like ocular diseases.

\section{Evidence Acquisition}

Bibliographical searches were performed in MEDLINE/ ScienceDirect/OVID up to October 2013 using the following keywords (all fields): ("metabolic syndrome" OR "Met syndrome”) AND [(ocular disease) OR (cataract) OR (glaucoma) OR (age-related maculopathy). 


\section{Results}

\subsection{Ocular Manifestation of MET Syndrome}

\subsubsection{Cataract}

One of the most important causes of vision loss is cataract. It is mainly seen in Asia $(18,19)$. Diabetes $(20,21)$ and hyperglycemia $(22,23)$ are risk factors for cataract. Researchers have reported a connection between specific metabolic irregularities including obesity, (24-26) blood pressure, $(27,28)$ lipid profile, $(29,30)$ and some types of cataract. Met syndrome is a risk factor for diabetes mellitus (DM), coronary artery disease (CAD) and cardiovascular disease (CVD) (31,32). Diabetes and hyperglycemia can induce cataract due to the development of glycation of lens proteins and osmotic effects of sorbitol that acts by absorption of water into the lens and the resulting hydration opacifies the lens (33). The mechanism linking HTN with cataract is not well understood. Inflammation and endothelial dysfunction could cause cataract in patients with $\operatorname{HTN}(34)$.

Tan et al. (7) showed that Met Syndrome is correlated with all the three types of cataract (nuclear, cortical, and posterior subcapsular). This evidence was reported in a cohort study among Australians (the blue mountain eye study). Furthermore, Paunksnis et al. (35) reported a connection between cataract and Met syndrome among middle-aged European people. In an Italian hospital based study, Met syndrome was shown to be in association with the probability of the need for cataract extraction (36).

Based on acceptable documents in many studies $(19,20$, $22,35,37$ ), hyperglycemia and diabetes are risk factors for cataract. Clinical observations confirm the findings of the Beaver Dam eye study (30), the Barbados eye studies $(23,38)$. These clinical studies suggest a relation between DM and both cortical and posterior subcapsular cataracts (PSC).

Sabanayagam et al. (39) reported that HTN, either alone or in combination with other Met syndrome components, was significantly associated with cataract. High BP was associated with cataract (either nuclear or cortical or posterior subcapsular subtypes) even among those without diabetes. He suggested that the Met syndrome and its two principal components, high BP and diabetes, are in relation with senile cataract in Malay population. These findings disclose the importance of modifiable risk of cataract. Some studies have found conflicting findings in the context of association between blood pressure, HTN, and cataract; high systolic BP was associated with cataract but high diastolic BP was not (18).

\subsubsection{Glaucoma}

One of the components of primary open angle glaucoma (POAG) is high intraocular pressure (IOP) (40). Ophthalmologists define IOP as a balance between aqueous secretion in posterior chamber and its outflow from tra- becular meshwork and uveoscleral pathway (41).

Open angle glaucoma (OAG) is one of the most important causes of irreversible blindness worldwide $(42,43)$. Understanding the risk factors associated with OAG development or progression will help clinicians identify which patients would gain the most benefit from screening and careful monitoring for the disease. Risk factors for OAG include elevated intraocular pressure (IOP), family history of OAG, and increased age.

1988-2000 National Health and Nutrition Examination Survey (NHANES) report that was a cross sectional health survey study showed that approximately $22 \%$ of Americans over the age of 18 met criteria for Met syndrome (11). Given the significant rise in hypertension, diabetes mellitus, hyperlipidemia, and obesity in recent years in the US, and the fact that even children and adolescents are affected by the obesity epidemic (44), it is essential for eye care providers to obtain a correct overview of the relationship between Met syndrome and chronic eye diseases including OAG. Many cross-sectional researches have shown association of increased IOP with cardiometabolic parameters $(45,46)$.

Chang et al. (47) analyzed the data from 1112 patients that underwent health checkup and concluded that people with Met Syndrome had a higher IOP than those without Met syndrome, and this difference was statistically significant. Their findings were consistent with those shown by Oh et al. (48) in the Korean population. There are several theories about possible mechanisms by which diabetes mellitus increases one's risk of developing OAG. Diabetes mellitus is a systemic disease, which is known to cause widespread vascular, autonomic, and endothelial dysfunction. Dysfunction of small blood vessels that have an important role in optic nerve nutrition may predispose the patient to glaucomatous damage to the optic nerve and retinal nerve fiber layer; oxidative damage from diabetes may lead to a similar result (49).

There are several proposed mechanisms explaining the relationship between hypertension and OAG. One theory suggests that elevated blood pressure leads to increased ciliary artery perfusion, resulting in increased aqueous production, which, in turn, increases the risk of developing $\operatorname{OAG}(50,51)$.

Another theory believes that many people with hypertension have arteriolosclerotic damage and stiffening of the small end vessels feeding the optic nerve, which may predispose them to experiencing glaucomatous optic neuropathy (52).

The third possibility includes damage to the optic nerve from decreased perfusion pressure caused during periods of episodic systemic hypotension related to blood pressure-lowering medication usage.

\subsubsection{Hyperlipidemia}

Basic science research in a trabecular meshwork cell culture model revealed that statins could increase aqueous 
outflow facility (53). Several studies have demonstrated a relationship between obesity and elevated $\operatorname{IOP}(45,54)$.

\subsubsection{Miscellaneous}

The results of some studies suggest that obesity can cause oculomotor nerve palsy and lower lid entropion consequently $(55,56)$. Sleep apnea, a condition related to obesity, has been seen with optic nerve head swelling, (57) and floppy eyelid syndrome (58).

\subsubsection{Retinal Microvascular Disorder}

Large and small vessel diseases such as inflammation and endothelial dysfunction have been reported to be associated with metabolic syndrome (58). The relationship between systemic hypertension and diabetes with retinal vascular diseases and other micro-vascular disorders is well known (6).

Wong reported that the possibility of retinopathy, arterial and venous crossing and narrowing of arterioles, were significantly more likely in people with Met Syndrome than people that do not suffer from this syndrome. Other factors including age, sex, level of education, race, smoking, and alcohol consumption didn't have an influence on this relationship (59).

Results of Kawasaki study among Japanese adults suggested that Met syndrome patients were more likely to have retinopathy (odds ratio is 1.64, 95\% CI: 1.02-2.64) compared with people without it (60). Prospective studies are warranted to determine the association between Met Syndrome and probability of developing retinopathy and other micro-vascular changes. One of the causes of acute vision loss is anterior ischemic optic neuropathy (AION). AION is divided into two groups: arteritic (AAION) and non-arteritic (NAION) (57). The NAION pathogenesis is not completely clear and different factors are suggested to be responsible $(61,62)$.

Obesity, hypertension, diabetes, dyslipidemia etc. are systemic risk factors that have an influence on blood circulation autoregulation of optic nerve head $(61,63)$. There may be a connection between Met syndrome and NA-AION. It was proved that one of the important parameters in the pathophysiology of NAION is optic disc structure (64). The risk of NAION is increased in patients with Met Syndrome due to synergistic effect of metabolic actors (62). These researches confirm the relationship between obesity and retinal vessel disease.

Studies have shown that there is no effective medical management for NAION. The incidence of AION in the fellow eye of affected patients is high, especially in young diabetic patients under 45 years old (61). Cardiovascular disease (CVD) is more prevalent in patients with Met Syndrome $(64,65)$. Along with these factors, the development of diastolic dysfunction includes increased BMI and diabetes (66). Early diagnosis and proper management of diastolic heart dysfunction can prevent further heart damage and even death. In a patient with NAION in association with Met syndrome, a multidisciplinary protocol is useful to recognize these risk factors. Immediate treatment of these patients can improve visual function and prevent cardiovascular complications.

\subsubsection{Central Retinal Artery Occlusion}

Arteriosclerosis, history of cerebrovascular accident, diabetes and systemic hypertension are associated with central retinal artery occlusion (CRAO) (67).

There is an evidence-supporting association of obesity with diabetes, hypertension, and hypercoagulable disorders, thus suggesting a relationship between CRAO and obesity (68).

\subsubsection{Age-Related Maculopathy}

Many studies have reported association between obesity and age-related macular degeneration (ARMD). The age related eye disease study (AREDS), a cross-sectional study, has shown a relationship between increase in BMI and ARMD in fundus photographs (69). Obesity increases oxidative stress that is one of the most important parts of the ARMD pathogenesis and it is induced by hyperleptinemia (70).

\section{Conclusions}

Today, the prevalence of Met syndrome is increasing, because world population life behaviors have changed. Its association with various ocular manifestations such as non-diabetic retinopathy, CRAO, cataract, and primary open angle glaucoma suggests that an epidemic of Met syndrome can have far-fetched ocular consequences as well. Amelioration of Met syndrome may have a substantial role in preventing these ocular conditions. However, most of the studies designed in this regard were cross-sectional studies, thus a causal relationship cannot be proven. Prospective interventional researches are required to confirm the relationship between Met syndrome or its components, and different ocular manifestations such as retinal micro vascular signs, cataract, and POAG.

\section{Acknowledgements}

Previous studies that were the basis for this review article was supported by Mashhad University of Medical Sciences Research Council.

\section{Authors' Contribution}

Authors contributed equally in this work.

\section{Financial Disclosure}

There is no financial interest.

\section{Funding/Support}

There is no funding source. 


\section{References}

1. Expert Panel on Detection ETOHBCIA. Executive Summary of the Third Report of the National Cholesterol Education Program (NCEP) Expert Panel on Detection, Evaluation, and Treatment of High Blood Cholesterol in Adults (Adult Treatment Panel III). JAMA. 2001;285(19):2486-97.

2. Mirhosseini NZ, Yusoff NA, Shahar S, Parizadeh SM, Mobarhen MG, Shakery MT. Prevalence of the metabolic syndrome and its influencing factors among adolescent girls in Mashhad, Iran. Asia Pac J Clin Nutr. 2009;18(1):131-6.

3. WHO Expert Consultation.. Appropriate body-mass index for Asian populations and its implications for policy and intervention strategies. Lancet. 2004;363(9403):157-63.

4. Yazdandoust S, Parizadeh SM, Moohebati M, Yaghmaei P, Rahsepar AA, Tavallaie S, et al. Serum small dense low-density lipoprotein concentrations are elevated in patients with significant coronary artery stenosis and are related to features of the metabolic syndrome. Lipids. 2012;47(10):963-72.

5. Farahmand SK, Gang LZ, Saghebi SA, Mohammadi M, MohammadiS, Mohammadi G, et al. The effects of wet cupping on coronary risk factors in patients with metabolic syndrome: a randomized controlled trial. Am JChin Med. 2012;40(2):269-77.

6. Wong TY, Klein R, Klein BEK, Tielsch JM, Hubbard L, Nieto FJ. Retinal Microvascular Abnormalities and their Relationship with Hypertension, Cardiovascular Disease, and Mortality. Surv Ophthalmol. 2001;46(1):59-80.

7. Tan JS, Wang JJ, Mitchell P. Influence of diabetes and cardiovascular disease on the long-term incidence of cataract: the Blue Mountains eye study. Ophthalmic Epidemiol. 2008;15(5):317-27.

8. Mitchell P, Smith W, Chey T, Healey PR. Open-angle Glaucoma and Diabetes. Ophthalmol.1997;104(4):712-8.

9. Dielemans I, Vingerling JR, Algra D, Hofman A, Grobbee DE, de Jong PTVM. Primary Open-angle Glaucoma, Intraocular Pressure, and Systemic Blood Pressure in the General Elderly Population. Ophthalmol.1995;102(1):54-60.

10. Ford ES, Giles WH, Dietz WH. Prevalence of the metabolic syndrome among US adults: findings from the third National Health and Nutrition Examination Survey. JAMA. 2002;287(3):356-9.

11. Ford ES. Prevalence of the metabolic syndrome defined by the International Diabetes Federation among adults in the U.S. Diabetes Care. 2005;28(11):2745-9.

12. Masoudi-Kazemabad A, Jamialahmadi K, Moohebati M, Mojarrad M, Manshadi RD, Akhlaghi S, et al. Neuropeptide Y Leu7Pro polymorphism associated with the metabolic syndrome and its features in patients with coronary artery disease. Angiol. 2013;64(1):40-5.

13. Azimi-Nezhad M, Herbeth B, Siest G, Dade S, Ndiaye NC, Esmaily H, et al. High prevalence of metabolic syndrome in Iran in comparison with France: what are the components that explain this? Metab Syndr Relat Disord. 2012;10(3):181-8.

14. George SJ, Johnson J. Atherosclerosis: molecular and cellular mechanisms.United States: Wiley-VCH;2010.

15. Kleemann R, Zadelaar S, Kooistra T. Cytokines and atherosclerosis: a comprehensive review of studies in mice. Cardiovasc Res. 2008;79(3):360-76.

16. Mallat Z, Ait-Oufella H, Tedgui A. Regulatory T-cell immunity in atherosclerosis. Trends Cardiovasc Med. 2007;17(4):113-8.

17. Tedgui A, Ait-Oufella H, Mallat Z. Cytokines and Atherosclerosis. In: George SJ, editor. Atherosclerosis: Molecular and Cellular Mechanisms. United States: Wiley; 2010.

18. Congdon NG, Friedman DS, Lietman T. Important causes of visual impairment in the world today. JAMA. 2003;290(15):2057-60.

19. Wong TY, Loon SC, Saw SM. The epidemiology of age related eye diseases in Asia. Br J Ophthalmol. 2006;90(4):506-11.

20. Klein BEK, Klein R, Lee KE. Diabetes, cardiovascular disease, selected cardiovascular disease risk factors, and the 5-year incidence of agerelated cataract and progression of lens opacities: the beaver dam eye study. Am J Ophthalmol.1998;126(6):782-90.

21. Saxena S, Mitchell P, Rochtchina E. Five-year incidence of cataract in older persons with diabetes and pre-diabetes. Ophthalmic Epidemiol. 2004;11(4):271-7.
22. Rowe NG, Mitchell PG, Cumming RG, Wans JJ. Diabetes, fasting blood glucose and age-related cataract: the Blue Mountains Eye Study. Ophthalmic Epidemiol. 2000;7(2):103-14.

23. Hennis A, Wu SY, Nemesure B, Leske MC, Barbados Eye Studies G. Risk factors for incident cortical and posterior subcapsular lens opacities in the Barbados Eye Studies. Arch Ophthalmol. 2004;122(4):525-30.

24. Weintraub JM, Willett WC, Rosner B, Colditz GA, Seddon JM, Hankinson SE. A prospective study of the relationship between body mass index and cataract extraction among US women and men. Int J Obes Relat Metab Disord. 2002;26(12):1588-95.

25. Schaumberg DA, Glynn RJ, Christen WG, Hankinson SE, Hennekens $\mathrm{CH}$. Relations of body fat distribution and height with cataract in men. Am J Clin Nutr. 2000;72(6):1495-502.

26. Jacques PF, Moeller SM, Hankinson SE, Chylack LJ, Rogers G, Tung W, et al. Weight status, abdominal adiposity, diabetes, and early age-related lens opacities. Am J Clin Nutr. 2003;78(3):400-5.

27. Schaumberg D. A Prospective Study of Blood Pressure and Risk of Cataract in Men. Annals Epidemiol. 2001;11(2):104-10.

28. Younan C, Mitchell P, Cumming R, Rochtchina E, Panchapakesan J, Tumuluri K. Cardiovascular disease, vascular risk factors and the incidence of cataract and cataract surgery: the Blue Mountains Eye Study. Ophthalmic Epidemiol. 2003;10(4):227-40.

29. Hiller R, Sperduto RD, Reed GF, D’Agostino RB, Wilson PWF. Serum lipids and age-related lens opacities: A longitudinal investigation. Ophthalmol. 2003;110(3):578-83.

30. Klein BE, Klein R, Lee KE. Cardiovascular disease, selected cardiovascular disease risk factors, and age-related cataracts: the Beaver Dam Eye Study. Am J Ophthalmol. 1997;123(3):338-46.

31. Alberti KG, Zimmet P, Shaw J. The metabolic syndrome-a new worldwide definition. The Lancet. 2005;366(9491):1059-62.

32. Azimi-Nezhad M, Ghayour-Mobarhan M, Safarian M, Esmailee H, Parizadeh SM, Rajabi-Moghadam M, et al. Anthropometric indices of obesity and the prediction of cardiovascular risk factors in an Iranian population. Scie World J. 2009;9:424-30.

33. Stitt AW. Advanced glycation: an important pathological event in diabetic and age related ocular disease. $\mathrm{Br} J$ Ophthalmol. 2001;85(6):746-53.

34. Klein BE, Klein R, Lee KE, Knudtson MD, Tsai MY. Markers of inflammation, vascular endothelial dysfunction, and age-related cataract. Am J Ophthalmol. 2006;141(1):116-22.

35. Paunksnis A, Bojarskiene F, Cimbalas A, Cerniauskiene LR, Luksiene DI, Tamosiunas A. Relation between cataract and metabolic syndrome and its components. EurJ Ophthalmol. 2007;17(4):605-14.

36. Galeone C, Petracci E, Pelucchi C, Zucchetto A, La Vecchia C, Tavani A. Metabolic syndrome, its components and risk of age-related cataract extraction: a case-control study in Italy. Ann Epidemiol. 2010;20(5):380-4.

37. Lindblad BE, Hakansson N, Philipson B, Wolk A. Metabolic syndrome components in relation to risk of cataract extraction: a prospective cohort study of women. Ophthalmol. 2008;115(10):1687-92.

38. Hiller R, Sperduto RD, Ederer F. Epidemiologic associations with nuclear, cortical, and posterior subcapsular cataracts. Am J Epidemiol.1986;124(6):916-25.

39. Sabanayagam C, Wang JJ, Mitchell P, Tan AG, Tai ES, Aung T, et al. Metabolic syndrome components and age-related cataract: the Singapore Malay eye study. Invest Ophthalmol Vis Sci. 2011;52(5):2397-404.

40. Lazaro C, Garcia-Feijoo J, Castillo A, Perea J, Martinez-Casa JM Garcia-Sanchez J. Impact of intraocular pressure after filtration surgery on visual field progression in primary open-angle glaucoma. EurJ Ophthalmol. 2007;17(3):357-62.

41. Civan MM, Macknight AD. The ins and outs of aqueous humour secretion. Exp Eye Res. 2004;78(3):625-31.

42. Quigley HA, Broman AT. The number of people with glaucoma worldwide in 2010 and 2020. Br J Ophthalmol. 2006;90(3):262-7.

43. Quigley HA. Number of people with glaucoma worldwide. $B r J$ Ophthalmol.1996;80(5):389-93.

44. Steinberger J, Daniels SR, Eckel RH, Hayman L, Lustig RH, McCrindle B, et al. Progress and challenges in metabolic syndrome in children and adolescents: a scientific statement from the Ameri- 
can Heart Association Atherosclerosis, Hypertension, and Obesity in the Young Committee of the Council on Cardiovascular Disease in the Young; Council on Cardiovascular Nursing; and Council on Nutrition, Physical Activity, and Metabolism. Circulation. 2009;119(4):628-47.

45. Lee JS, Lee SH, Oum BS, Chung JS, Cho BM, Hong JW. Relationship between intraocular pressure and systemic health parameters in a Korean population. Clin Experiment Ophthalmol. 2002;30(4):237-41.

46. Memarzadeh F, Ying-Lai M, Azen SP, Varma R, Los Angeles Latino Eye Study G. Associations with intraocular pressure in Latinos: the Los Angeles Latino Eye Study. Am J Ophthalmol. 2008;146(1):69-76.

47. Chang YC, Lin JW, Wang LC, Chen HM, Hwang JJ, Chuang LM. Association of intraocular pressure with the metabolic syndrome and novel cardiometabolic risk factors. Eye (Lond). 2010;24(6):1037-43.

48. Oh SW, Lee S, Park C, Kim DJ. Elevated intraocular pressure is associated with insulin resistance and metabolic syndrome. Diabetes Metab Res Rev. 2005;21(5):434-40.

49. Szaflik JP, Rusin P, Zaleska-Zmijewska A, Kowalski M, Majsterek I, Szaflik J. Reactive oxygen species promote localized DNA damage in glaucoma-iris tissues of elderly patients vulnerable to diabetic injury. Mutat Res. 2010;697(1-2):19-23.

50. Bulpitt CJ, Hodes C, Everitt MG. Intraocular pressure and systemic blood pressure in the elderly. Br J Ophthalmol. 1975;59(12):71720.

51. Shiose Y, Kawase Y. A new approach to stratified normal intraocular pressure in a general population. Am J Ophthalmol. 1986;101(6):714-21.

52. Wolf S, Arend O, Sponsel WE, Schulte K, Cantor LB, Reim M. Retinal hemodynamics using scanning laser ophthalmoscopy and hemorheology in chronic open-angle glaucoma. Ophthalmology. 1993;100(10):1561-6.

53. Song J, Deng PF, Stinnett SS, Epstein DL, Rao PV. Effects of cholesterol-lowering statins on the aqueous humor outflow pathway. Invest Ophthalmol Vis Sci. 2005;46(7):2424-32.

54. Klein BE, Klein R, Linton KL. Intraocular pressure in an American community. The Beaver Dam Eye Study. Invest Ophthalmol Vis Sci. 1992;33(7):2224-8.

55. Teuscher AU, Meienberg O. Ischaemic oculomotor nerve palsy. Clinical features and vascular risk factors in 23 patients. J Neurol. 1985;232(3):144-9.

56. Raina J, Foster JA. Obesity as a cause of mechanical entropion. Am
J Ophthalmol.1996;122(1):123-5

57. Purvin VA, Kawasaki A, Yee RD. Papilledema and obstructive sleep apnea syndrome. Arch Ophthalmol.2000;118(12):1626-30.

58. McNab AA. The eye and sleep. Clin Experiment Ophthalmol. 2005;33(2):117-25

59. Wong TY, Duncan BB, Golden SH, Klein R, Couper DJ, Klein BE, et al. Associations between the metabolic syndrome and retinal microvascular signs: the Atherosclerosis Risk In Communities study. Invest Ophthalmol Vis Sci. 2004;45(9):2949-54.

60. Kawasaki R, Tielsch JM, Wang JJ, Wong TY, Mitchell P, Tano Y, et al. The metabolic syndrome and retinal microvascular signs in a Japanese population: the Funagata study. Br J Ophthalmol. 2008;92(2):161-6.

61. Hayreh SS. Ischaemic optic neuropathy. Indian J Ophthalmol. 2000;48(3):171-94.

62. Nguyen TT, Wong TY. Retinal vascular manifestations of metabolic disorders. Trends Endocrinol Metab. 2006;17(7):262-8.

63. Monteiro ML. Anterior ischemic optic neuropathy: a comparison of the optic disc area of patients with the arteritic and non-arteritic forms of the disease and that of normal controls. Arq Bras Oftalmol.2006;69(6):805-10.

64. Grundy SM, Hansen B, Smith SCJ, Cleeman JI, Kahn RA, American Heart A, et al. Clinical management of metabolic syndrome: report of the American Heart Association/National Heart, Lung, and Blood Institute/American Diabetes Association conference on scientific issues related to management. Arterioscler Thromb Vasc Biol. 2004;24(2):e19-24.

65. Grundy SM, Cleeman JI, Daniels SR, Donato KA, Eckel RH, Franklin BA, et al. Diagnosis and management of the metabolic syndrome: an American Heart Association/National Heart, Lung, and Blood Institute scientific statement: Executive Summary. Crit Pathw Cardiol. 2005;4(4):198-203.

66. de Simone G. State of the heart in the metabolic syndrome. Nutr Metab Cardiovasc Dis. 2005;15(4):239-41.

67. Mangat HS. Retinal artery occlusion. Surv Ophthalmol. 1995;40(2):145-56.

68. Abramson N, Abramson S. Hypercoagulability: clinical assessment and treatment. South Med J. 2001;94(10):1013-20.

69. Age-Related Eye Disease Study Research G. Risk factors associated with age-related macular degeneration. A case-control study in the age-related eye disease study: Age-Related Eye Disease Study Report Number 3. Ophthalmology. 2000;107(12):2224-32.

70. Bouloumie A, Marumo T, Lafontan M, Busse R. Leptin induces oxidative stress in human endothelial cells. FASEB J.1999;13(10):1231-8. 